\title{
Pragmatic and Semantic Potential of Newspaper Headlines*
}

\author{
Hind M. Ismail \\ Anbar University, Anbar, Iraq
}

\begin{abstract}
This paper aims at throwing a light on the interrelationship of pragmatics and semantics in terms of avoiding misunderstanding and miscommunication between the speaker/writer and hearer/reader. For this purpose, we restrict the sphere with the analysis of headlines from $\mathrm{BBC}$ news whose meanings are interpreted by using presuppositional and entailment techniques. Although semantics is concerned only with the literal meaning of the words and their interrelations, pragmatic usage pays attention to the importance of the so called inferred meaning that the speakers and listeners perceive. Presupposition and entailment refer to two different aspects of information. In presupposition, it is the speakers' circumstantial knowledge while in entailments, it is a conclusion that speakers arrive as a definite type of consequence. Headlines subjectively give clues about or express the most important aspect of the text combining in themselves both semantic and pragmatic meanings and for our analysis of discourse, we will refer to media as a specific form of discourse that is itself a power resource and how media can influence people's minds, e.g., their knowledge or opinions, revealing integration of among which is the major concerns of the paper. The study, with this in mind, explores the potential of semantics and pragmatic modules introduced by $\mathrm{T}$. Van Dijk.
\end{abstract}

Keywords: semantics, pragmatics, presupposition, entailment, context, headline

\section{Introduction}

This study investigates sociopragmatic interactional principles and choice of linguistic strategies applied in the article is based on the major concern of which the annexation of the Crimea by the Russian federation. To this end, the reporter administered the so-called "questionnaire" (oral questioning) to a bilingual citizen of the Crimea who had a mixed family (himself as a Russian and his Ukrainian wife), whose information about the past and present can hardly be regarded as the key to truthfulness of the nature of the political reasons which enacted in the article in favor of the Russian Government, and often not clear and convincing for seeing the occupation of the country logically reasonable.

The person, whom the journalist uses, is the tourist guide who is the narrator and the only "source" in this reporting that does not represent equally all social groupings in the population: The neglect of the opinions of the Crimean Tatars and the people of Ukrainian nationality completely makes it relatively clear "whose perspective" has been considered significant in the article. The linguistic aspects of the article (coherence, relevance, structuring) are also among the major concerns of the article. As readers, headlines attract our attention by evoking interest to the content of the body of the article. A headline is a dependent form of

\footnotetext{
${ }^{*}$ Acknowledgements: My thanks and gratitude to my supervisor Prof. Dr. Huseynaga Rzayev.

Hind M. Ismail, lecturer, Anbar University; Ph.D. student, Department of English Language and Literature, Suleyman Demirel University.
} 
newspaper writing as a part of a larger whole. It provides markers for the content of the article to satisfy the reader's curiosity. The main function of headlines is to inform the reader briefly about the text that follows. They also signal of the paper's attitude to the facts reported (Galperin, 1977).

For our analysis of discourse, we will refer to media as a specific form of discourse that is itself a power resource and how media can influence people's minds, e.g., their knowledge or opinions about the situation in Crimea.

Critical discourse analysis focuses on how discourse structures influence mental representations. At the global level of discourse, topics may influence what people see as the most important information of text or talk, and thus correspond to the top levels of their mental models. For example, expressing such a topic in a headline in news may powerfully influence how an event is defined in terms of a "preferred" mental model. Similarly, argumentation may be persuasive because of the social opinions that are "hidden" in its implicit premises and thus taken for granted by the recipients. In our example, the narrator tries to show that the annexation of Crimea by Russia is legal (Van Dijk, 2001)

\section{Method}

The data is an article from the $\mathrm{BBC}$ website. The headline of the article will be analyzed in relation to the content of the article in terms of pragmatic and semantic aspects according to Van Dijk's approach, and how context as a study of critical discourse analysis that is itself a power resource that influences people's minds.

\section{Limitation of the Study}

For our analysis of discourse, we will refer to the context of media as a specific form of discourse that is itself a power resource, and how media can influence people's minds, e.g., their knowledge or opinions about the situation in Crimea according to our article. Van Dijk's sociocognitive approach of context will be depended on in our analysis.

"One-sidedness" of the article finds its reflection in one more aspect: Taking this citizen as an ideal source, the reporter, in fact, has deprived himself from determining what is included and excluded and how the events are represented. Accordingly, the following question arises: Whether or not the article (and the newspaper) transmits someone else's representation? And if so, does not that give a certain amount of power to and justify the aggression of that "someone else"?

\section{Discourse and Critical Discourse Analysis}

Van Dijk (1980) defines discourse analysis as the analysis of structures and functions of actual forms of language use. He states that discourse is an utterance type of natural language which realizes a sequence of sentences which satisfies a number of properties. These properties are not only related to the grammatical features, but also to the semantic and pragmatic aspects of the textual nature of the sequences of sentences which are expressed by a discourse.

Critical discourse analysis (CDA) is a type of discourse analytical research that primarily studies the way social power abuse, dominance, and inequality are enacted, reproduced, and resisted by text and talk with the social and political context (Van Dijk, 2001).

CDA also focuses on how discourse structures influence mental representations. At the global level of discourse, topics may influence what people see as the most important information of text or talk, and thus correspond to the top levels of their mental models. For example, expressing such a topic in a headline in news 
may powerfully influence how an event is defined in terms of a "preferred" mental model. Similarly, argumentation may be persuasive because of the social opinions that are "hidden" in its implicit premises and thus taken for granted by the recipients. In our example, the narrator tries to show that the annexation of Crimea by Russia is legal (Van Dijk, 2001).

Power is considered as a central notion in most critical work on discourse, and more specifically the social power of groups or institutions, and Van Dijk defines the social power in terms of control. Thus, groups have (more or less) power if they are able to (more or less) control the acts and minds of (members of) other groups, and we will notice this power in our example we have the power of media. This ability presupposes a power base of privileged access to scarce social resources, such as force, money, status, fame, knowledge, information, "culture", or indeed various forms of public discourse and communication (Van Dijk, 2001).

The control of group power is not only a control over the content, but over the structures of text and talk. Relating text and context, thus, members of powerful groups may decide on the (possible) discourse genre(s) or speech acts of an occasion. Van Dijk (2001) defines context as "the mentally represented structure of those properties of the social situation that are relevant for the production or comprehension of discourse" (p. 356), and controlling context involves control over one or more of these categories, e.g., determining the definition of the communicative situation, deciding on time and place of the communicative event, or on which participants may or must be present, and in which roles, or what knowledge or opinions they should (not) have, and which social actions may or must be accomplished by discourse (Van Dijk, 2001).

In addition, given a specific context, certain meanings and forms of discourse have more influence on people's minds than others. Contextually based control derives from the fact that people understand and represent not only text and talk, but also the whole communicative situation. Thus, CDA typically studies how context features (such as the properties of language users of powerful groups) influence the ways members of dominated groups define the communicative situation (Van Dijk, 2001).

\section{Semantic and Pragmatic Features of Discourse}

Semantics and pragmatics deal with the meaning of language and link language to the world. Each branch deals with meaning differently; yet, many students of linguistics confuse the two terms. The only obvious similarity between the two branches is that they both deal with the meanings of words and sentences but in different ways (Hurford \& Smith, 2007).

Semantically, the headline can be interpreted due to its literal meaning and inferences that readers reach depending on their cognitive knowledge. In order to demonstrate the meaning in its full efficiency, pragmatic aspects are also helpful in specifying the purpose of the article by making appropriate sense.

Although the headline highlights the main idea for an article, the latter at the same time must have a specific language style for persuasion of the reader and for this purpose provide him with the reporter's personal evaluation of the published information (Galperin, 1977). The article also must have features of coherence to reflect the unity of the text in relation to the headline's theme. The writer can use different stylistic devices such as discourse markers and connectors, metaphors, rhetorical questions, and emotive words to facilitate the interpretation of the utterances and attract readers' attention.

The fields of semantics and pragmatics are integrally related to one another. For example, some categories in semantics require the application of pragmatics in order to arrive at a satisfactory interpretation. Deictic 
words, for instance, take some elements of their meanings from the context in which they are uttered (Hurford $\&$ Smith, 2007).

For Lyons (1977), semantics is a branch of knowledge that is concerned with meaning, whereas Levinson (1983) defined pragmatics as a branch of knowledge that is concerned with language use. Pragmatics involves the procedural process with the focus on the connection between the language uttered, and the context in which it is used while semantics entails the conceptual process by concentrating on the meaning of expressions (Blakemore, 2002). Language users know or assume that recipients are able to infer these implied propositions on the basis of generally shared knowledge, and thus construe a mental model for the discourse.

The definition of implications (implied propositions of a discourse) is thus very straightforward: Not all the propositions of a situation model are expressed in the discourse explicitly (Van Dijk, 2012). Presuppositions can be defined as propositions which are accepted as true for other propositions to be meaningful (Krahmer, 1998). Whereas implications, unlike the above discussed entailments, are inferred as consequences of the interrelationship of propositions in a discourse; presuppositions are like the conditions of propositions, as is the case for all prior knowledge. Thus, presuppositions are implied propositions following from earlier parts of the discourse, the situation model, the context model or by inferences from general knowledge, thus making following expressions (words, phrases, clauses, sentences, etc.) meaningful (Hurford \& Smith, 2007).

Interpreting utterances involve a considerable amount of guesswork. The hearer has to draw inferences from the speaker's words to arrive at the speaker's intended meaning. Entailment is a relationship between sentences that form the basis for some of these inferences. We do not expect people to tell us something that we are unfamiliar with, as claimed by some linguists, in every sentence, there is a certain amount of embedded, but understood information that comes from our knowledge of the language itself (Saeed, 2008). Therefore, semantics and pragmatics both deal with meaning and interpretation of a text. Semantics deal with literal meaning and inferences by the readers, while pragmatics deals with the aspects of the context and principles and devices of interpretation such as presupposition and Implicature (Lyons, 1977).

\section{Headlines in Discourse}

"Headline describes the essence of complicated news story in a few words. It informs quickly and accurately and arouses the reader's curiosity" (Ungerer, 2000, p. 48). News headlines are particularly important for the way readers comprehend a news text; they are markers that orient monitor attention, perception, and the reading process (Van Dijk, 1988). According to Sheyholislami (2001), themes and rhemes are briefly realized in the headlines and lead paragraphs. For Dijk (1998), headlines depict the unity of discourse as a source of information; and the readers with their own beliefs and ideas generally adopt the suggested media definitions of how important and capacious the published information about an event is. Kress (1990) argues that the defined statements not only express but also are organized for a definite ideological purpose. Newspaper headlines act as a forerunner to news reports more than that, headlines expose the social, cultural, and national representations and often headlines are considered by the audience more essential than the news articles. Their impact is likely to be more upon the readers due to certain linguistic features which make them memorable and effective (Develotte \& Rechniewski, 2001).

Claude (1980) (as cited in Develotte \& Rechneiwski, 2001) states that newspaper headlines not only put the content in a nutshell, but also give clues about how to decode the messages in them. Understanding the unity of the presupposed and perspective information enables the reader to understand the social and cultural 
references adequately. Headlines as a part of the whole signals about the facts in the news article while the article carries the principal vehicle of interpretation and appraisal (Galperin, 1977). For better understanding the so-called "labor division" between the headline and its article, the contribution of pragmatic and semantic aspects also must be considered thoroughly.

\section{Van Dijk's Approach of Context}

From a socio-cognitive view, Van Dijk (2009) focuses on the cognition and the mental representations of context. He defines context as the way participants as speakers (writers) and recipients subjectively understand, interpret, construct, or represent these social characteristics of social situations that influence their production or understanding of their talk or text. It is this scope that he thinks essential in the context of text and talk, since in the same communicative event, participants may interpret the various aspects of the social situation in different ways. His contention is that "a context is what is defined to be relevant in the social situation by the participants themselves" (p. 4).

Van Dijk (2007) states that text and talk require vast amount of knowledge, language users in interaction only say what is relevant to the situation, leaving a host of meanings or inferences implicit, either because the meanings or the inferences are in the current situation irrelevant, inappropriate, or because they can be inferred by the recipient.

Therefore, the understanding of text or talk involves not only the construction of its meaning (or intension) in terms of some semantic representation, but also the construction of its referents (or extension) in terms of mental models stored in Episodic Memory. Conversely, talking or writing about specific events, as is the case for storytelling or news reports is based on the personal, subjective, situation models language users construe of such events (Van Dijk, 2013).

According to the social representation, Van Dijk (2007) points out that context models are related to general, shared social representations which include sociocultural, group knowledge, attitudes, norms, values, ideologies, and other forms of social cognition members share with other members of the same social group or community. These social representations play a role in the very construction of new context models, and depending on these representations, language users can learn from their everyday experiences, perspectives on social cognition, social representations and other forms of socially shared beliefs. He states also that in addition to the importance of social knowledge, language users need semantic and pragmatic knowledge of the language.

Van Dijk (2009, p. 25) states that contexts as mental models of relevant communicative situations are not just personal interpretations of situations, but are also based on socially shared understandings of time, place, participants, and their roles and identities, relations of power, and so on.

Van Dijk (2009) pointed out that,

To facilitate understanding, interaction or communication, context should feature a relatively small number of basic categories: setting, participants, and actions. Similarly, the main relevant social properties of the participants (e.g., gender, age, political party, etc.) may be represented in the model, as well as their current knowledge and opinions. (p. 131)

And he also describes context according to two levels to describe the social situation, it can be either local (micro) or global (macro).

Local refers to "the immediate situation of actual discourse production and understanding. E.g., Face to face interaction which involves the presence of individual persons as participants". 
Global refers to "the broader historical, societal or culture situation described not only in terms of the current participants, but also in terms of groups, communities or institutions, and not limited to the time or the place of the actual utterance but involving a larger period and a larger location" (Van Dijk, 2007, p. 286).

According to semantics and pragmatics of the language, Van Dijk (2007) mentions that the knowledge (in mental model and social representations) helps participants to form two models (knowledge); pragmatic model, i.e., contexts defined as subjective mental models of communicative situations can also easily be linked with the (semantic) mental models that represent the subjective meaning' interpretation of text and talk, and referentially what the text or talk is about.

So, according to Van Dijk, context (text or talk) is analyzed depending on knowledge or the mental representation of the users and this knowledge consists of: pragmatic and semantic knowledge, social knowledge, as well as their previous knowledge of any subject and their attitudes and cultural background. All these different kinds of knowledge lead to a good interpretation and understanding of the situation which affects their production and understanding.

\section{Data Analysis}

In this section, a headline with its article from BBC news will be analyzed in terms of semantic and pragmatic aspects.

The reporter divided the article into four parts, each with a headline depending on a set of events in the country. The first two parts with the headlines "last stand" and "lost empire" are coherent because of the sequences of events and temporal devices which consolidate the unity of the text. The coherence of the introduction part dealing with the annexation of Crimea has been provided by the impression of the local Russian inhabitant in the third part of the article entitled "first impression". The final part entitled "garden tour" is concerned with the existing tension relation between Crimea and Ukraine, which, as he expects, will take years to get normalized again.

As the reporter states that "When Russia annexed Crimea from Ukraine this month, the Kremlin must have calculated that whatever the consequences abroad, it would be a popular move at home as well as in Crimea itself", therefore, the "returning" of Crimea to Russia will call for the essential consequences both inside the country and in the whole world. To give seriousness to the text, the author uses the so-called dry or neutral style which is appropriate for truth-value propositions semantically varying in accord with the changing character of the text. Using various discourse connectives serves to unify the parts of the article, while using adjectives strengthens and intensifies not only the beauty of the Crimea, it also gives the anxiety of the people who are uncertain about the influences of these unexpected events.

The author refers to the historical ties which bind Russia with Crimea. Using specific vocabulary items such as "bloody sieges", "steeped in Russian blood", etc., aims to enhance the impression to "shadow" the real truth and convince the readers. He also tries to control and affect readers' mind through mentioning information which is known and information which may be unknown and considered new for the readers. The fact that the author uses a rhetorical question "who better to reveal this rich history than a veteran Sevastopol tour guide?" as a stylistic device to inform the reader about the best person who can narrate the historical events, a Russian tour guide, is another "trap" for "masking" the real state of things in the region. The author divided the events narrated by the tour guide into four parts with subtitles in accord with the sequences of the historical events which provide the coherence of the text, i.e., thread these parts into the whole article. The historical ties here 
represent the background and mutual knowledge of the writers and the readers, which help understand the situation of the article.

The headline of the first part of the article is "last stand", the headline presupposes the historical period and events of the Second World War. The Russian guide mentions some war events and sacred places and uses, such emotive words as "desperate, impressive" to affect the readers. The discourse markers "first, next" reflect the sequences of the events; they have been used appropriately, make sense and give unity to the text to reflect the semantic aspects of cohesion and coherence.

The second headline of the second part is "lost empire" and begins with the words "third and final" to complete the previously mentioned events, which, in fact, bring the two parts together and entail each other which are helpful in providing unity. The presupposition of the war events and how Russia lost her dominance in the Black sea are also closely related to and supposed by the headline, at the same time contributing to the unity of the text.

The third part of the article, entitled as "first impression". The headline here reflects the impression of the Russian tour guide. So, it is a subjective and individual impression. For the tour guide, Russian people in Ukraine want to be part of Russia. Then he used a metaphor saying that Ukraine is a "wicked stepmother" which reflects the Russian people's feelings and impressions and which has implied meaning that must be understood by the readers depending on their knowledge of the situation in Ukraine. Using different discourse connectives, a rhetorical question, and metaphors which make text coherent and reflect the title's semantic meaning, the author is trying to make his ideas more emphatic and convincing the readers.

Finally, the last part of the article entitled as "garden tour". The headline here has been enriched by the metaphor "Crimea is a garden" and it needs water and that Ukraine is the source of water and energy for Crimea. The author has also used many discourse connectives and markers such as "but", "while", "as", "when", "and", etc., to reflect the interrelatedness of the ideas.

The writer begins his article with an introduction about the annexation of Crimea by Russia, which involves the historical claims between the two sides. His interpretation wholly rests on a Russian tour guide's opinion on Russia's right in taking Crimea, which can hardly be considered objective and reliable.

The language of the article used is purposeful; the historical sequence of events mentioned by the Russian tour guide is a tool to affect people. The metaphors used in the article serve to facilitate the conception of facts while emotive words are applied to enhance the emotional appeal; as for discourse connectives and markers, they illustrate the process of grasping the correlation of ideas, which serve one purpose to persuade the readers.

The subjectivity and one-sidedness in the treatment of the eventive theme wholly depend on the facts narrated by the Russian tour guide. As for the use of personal pronouns "he" and "she", it justifies a personal approach to the problem treated.

The narrator here is the man who has been working as a tour guide and whom the reporter depends on in getting information concerning the historical events and vision about Russia and Crimea. In fact, it is the tour guide's vision of the current situation. So, the guide's opinion is dominant in understanding the reasons and sources of historical relation between Russia and Crimea.

The words of the headline refer to the crisis between Russia and Ukraine because of the annexation of the Crimea by Russians. A guide's opinion reflects and mirrors the Russia's vision. So, the headline gives the reader a clue through which the article will be connected with a reference to the vision that the reader will discover in the article. Therefore, the clues in the headline presuppose information that helps readers activate 
their knowledge in relation to the context of the article. The writer assumes that the readers already know about the situation of Ukraine and Russia since it is part of the readers' social and cultural knowledge as it is mentioned by the narrator when he mentioned the historical events in the article. The writer presupposes assumptions which may be true or mistaken but mostly they are appropriate to the context of the situation. So, the context (pragmatic model) which is the mental representations of the readers with the semantic aspects such as entailments, references, lexical items together help the readers to understand and build inferences about the situation in Ukraine.

Pragmatically, the Ukraine crisis presupposes as everlasting claims about Crimea, which functions as background information in justifying the annexation; these claims, in fact, are nothing but implicit hints which can be easily "demasked" after reading the whole article.

According to the general categories of the context of the article, the narrator mentioned historical time such as "10th century" and locations such as the "site of the ancient Greek colony". For participants, there are different entities such as "Soviet troops", "Ukraine", "Vladimir Lenin", etc. For the topic we have the article is about "Ukraine crisis", and finally, the activity on here is "narrating". All these categories are reflected in the knowledge of the readers about the social and cultural situation in the article.

For the structure of context according to society, we have the local and the global situation. For the local context, we have the immediate situation of a narrator who works as a tourist guide in Crimea and whom the writer depends on to narrate the history of Crimea, while as a global, we have the writer as an institute or media that has the power to affect people through his article, and the narrator as a Russian who gives Russia the right to occupy Crimea. So, we have here a social power which has the ability to control people's minds through its power of discourse (context).

\section{Conclusion}

According to Van Dijk's approach, it is clear that language users depend completely on their general knowledge, background knowledge, and shared knowledge to reach to a good interpretation of a text. Semantic and pragmatic knowledge which are part of the users' cognition of their language play an important role in interpreting cues and markers in the headline and the text and relate them to their knowledge to comprehend the idea of the text and reach to the idea that the writer wants to say.

This paper can show the following results:

(1) Headlines contain different pragmatic and semantic aspects. They presuppose ideas and make readers activate their general knowledge to arrive at proper inferences.

(2) Headline is part of a whole, i.e., it is part of an article that provides the readers with interpretations and information related to the headline.

(3) The main function of headlines is to inform the reader briefly about the text that follows, and at the same time, the context helps clarify the presuppositions of the headline and make readers activate their knowledge to arrive at proper inferences.

(4) The aim of publicistic style is to exert a deep influence on public opinion and convince readers to accept the point of view expressed in the article, the realization of either of which can hardly be regarded as a success.

(5) Through the semantic knowledge of the readers (references, metaphors, entailments, coherence, cohesion, etc.), the reader will be able to draw inferences from to arrive at the writer's intended meaning. 
(6) Pragmatic knowledge help readers through their mutual knowledge about culture, society and their pragmatic knowledge of language understand the context of the situation.

(7) It is clear that context features as part of critical discourse can influence and control people's minds, e.g., their knowledge or opinions.

\section{References}

Blakemore, D. (2002). Relevance and linguistic meaning: The semantics and pragmatics of discourse markers. Cambridge: Cambridge University Press.

Develotte, C., \& Rechniewski, E. (2001). Discourse analysis of newspaper headlines: A methodological framework for research into national representations. Journal of French Media Studies, 4.

Galperin, I. R. (1977). Stylistics. Moscow: Higher School.

Hurford, J., Heasley, B., \& Smith, M. (2007). Semantics (2nd ed.). Cambridge: Cambridge University Press.

Krahmer, E. (1998). Presupposition and anaphora. Stanford, CA: Center for the Study of Language and Information, Leland Stanford Junior University.

Kress, G. (1990). Critical discourse analysis. In R. Kaplan (Ed.), Annual review of applied linguistics (Vol. II). Oxford: Oxford University Press.

Levinson, C. S. (1983). Pragmatics. Cambridge: Cambridge University Press.

Lyons, J. (1977). Semantics. Cambridge: Cambridge University Press.

Saeed, J. (2008). Semantics: Introducing linguistics. UK: Wiley-Black Well.

Sheyholislami, J. (2001). Critical discourse analysis (Unpublished manuscript, Carleton University, Ottawa). Retrieved October 10, 2015 from http://www.server.carleton.ca/jsheyhol/articles/what\%20is\%20CDA.pdf

Ungerer, F. (Ed.). (2000). English media texts-past and present language and textual structure. Philadelphia PA: John Benjamins.

Van Dijk, T. A. (1980). The semantics and pragmatics of functional coherence in discourse. In A. Ferrara (Ed.), Speech act theory: Ten years later (pp. 49-65). Milano, Italy: Versus.

Van Dijk, T. A. (1988). News as discourse. Hillsdale, NJ.: Lawrence Erlbaum.

Van Dijk, T. A. (2001). Critical discourse analysis. In D. Schiffrin, D. Tannen, and H. Hamilton (Eds.), Handbook of discourse analysis (pp. 352-271). UK: Blackwell.

Van Dijk, T. A. (2007). Comments on context and conversation. In N. Fairclough, G. Cortese, and P. Ardizzone (Eds.), Discourse and contemporary social change (pp. 281-316). Bern: Peter Lang.

Van Dijk, T. A. (2009). Society and discourse: How social contexts influence text and talk. UK: Cambridge University.

Van Dijk, T. A. (2012). Discourse and knowledge. In J. P. Gee and M. Hanford (Eds.), Handbook of discourse analysis (pp. 587-603). London: Routledge.

Van Dijk, T. A. (2013). Current state and prospects of the socio-cognitive approach to discourse. In C. Hart and P. Cap (Eds), Contemporary studies in critical: Analysis discourse-cognition-society (Version 3.1). Barcelona: Pompeu Fabra University.

\section{Appendix}

The newspaper article: 4/5/2014 BBC News-Ukraine Crisis: A Guide to Russia's Vision of Crimea. EUROPE, 25 March 2014 last updated at 02:04 GMT. http://www.bbc.com/news/world-europe-26695808 1/2.

\section{Ukraine Crisis: A Guide to Russia's Vision of Crimea}

When Russia annexed Crimea from Ukraine this month, the Kremlin must have calculated that whatever the consequences abroad, it would be a popular move at home as well as in Crimea itself. Russian bonds to the peninsula stretch back more than two centuries, over a timeline punctuated by bloody sieges of Sevastopol. One remark you constantly hear is that Crimea is historically "steeped in Russian blood". Another important tie, less tragic, goes back to pre-Tatar, medieval times. It is a lot to take in, but who better to reveal this rich history than a veteran Sevastopol tour guide? 


\section{Last Stand}

In Soviet times, Alexander Ivashevsky led busloads of tourists on nine-hour excursions around the "city of 1,500 monuments", following an approved trail and keeping more or less to an approved commentary. Now aged 64, the retired guide agreed to draft his own tour, in half the time. His first stop is the 35th Battery, an underground coastal gun emplacement which saw ferocious fighting in June-July 1942, as Soviet troops made a last stand against the advancing Nazis. A desperate attempt was made to evacuate through the battery's sea exits. Soldiers waited without drinking water on the rocks in the sun, as corpses of comrades floated around them. For Mr Ivashevsky, the descent through the ruined battery's dank corridors is a solemn pilgrimage in memory of the war dead. His next destination, the sun-drenched site of the ancient Greek colony of Chersonesus, is a more traditional kind of pilgrimage. Amid the impressive Greek and Byzantine stone structures that litter Crimea's answer to Pompeii, a cathedral marks the spot where Vladimir the Great is said to have been baptised in the 10th Century. As the ruler who brought Christianity to what are now Ukraine and Russia, he is revered by Orthodox Christians like Mr Ivashevsky, who inhales the air of Chersonesus like a tonic.

\section{Lost Empire}

The third and final stop is on a hill in the very centre of Sevastopol — not the eye-catching statue of Soviet leader Vladimir Lenin there, but another cathedral, small and elegant. Russian naval commanders killed during the Crimean War with Britain, France and Turkey were brought here for burial during the first siege of Sevastopol (1854-55), when the Admiralty Cathedral was still only being built. Interred along with them is the Russian explorer Admiral Mikhail Lazarev, who commanded a ship on the Russian expedition which discovered Antarctica for the world in 1820. Its facade still pocked by shell and bullet holes from the later war, the cathedral is one of a handful of buildings in Sevastopol to have survived World War Two, It is a poignant link to Imperial Russia, a civilisation which melted into the Black Sea in 1920 with the evacuation of the tsarist White Army and the arrival of the Soviets.

\section{First Impression}

Alexander Ivashevsky knows his stuff, but what does it matter to anyone below the age of 22 in Crimea? There may be younger ethnic Russian Crimeans who wanted to stay in Ukraine, having never known any other country, he accepts. But he believes the "overwhelming majority" wanted reunification with Russia. For him, Ukraine is a "wicked stepmother" who promised Crimean Russians a better life after independence in 1992, then "deceived" them. In all those 22 years, he says, he “never felt Ukrainian". The deciding factor for Mr Ivashevsky this winter was the new Ukrainian parliament's attempt to remove the status of Russian as an official second language. While that attempt was quickly blocked by the new president, "first impressions count", as another ethnic Russian put it. Contending controversially that everyone in Ukraine understands Russian, an indignant Mr Ivashevsky asks: "Is there any other country on Earth where a language understood by $100 \%$ of the population is not a language of state?"

What, he asks, is an old woman to do when she goes to buy medicine in a chemist's shop and cannot read the instructions because they are written in Ukrainian? Why not a multilingual Ukraine like Canada or Switzerland?

\section{Garden Tour}

Alexander Ivashevsky's wife is from Ukraine and all her roots, all her extended family, are there. She did not welcome the referendum on joining Russia and she is now very worried, he says. Strictly speaking, the first stop on the excursion was a charming garden the couple had cultivated together in the courtyard of the block of flats where they live: almond, walnut and cherry trees. "Enough walnuts to feed our pet Belgian rabbit all winter", according to a proud Mr Ivashevsky. Of course, trees depend on water and Crimea depends on Ukrainian pipes for its water and energy supplies. Mr Ivashevsky expects the next few years to be hard but he remains hopeful. For a Crimean with a keen sense of history, he evidently tries to keep things in proportion. 